\title{
TINJAUAN HUKUM ISLAM TERHADAP GADAI TANAH DENGAN KURS HARGA EMAS (Studi Kasus di Desa Plakpak Kecamatan Pegantenan)
}

\author{
Sihabuddin \\ Wasilatur Rohmaniyah \\ (Fakultas Syariah IAIN Madura Jl. Raya Panglegur Km. 4 Pamekasan 69371, \\ email:wasilatur@iainmadura.ac.id)
}

\begin{abstract}
Abstrak:
Gadai tanah dengan kurs harga emas di desa Plakpak terjadi dengan sistem pembayaran di mana pemberi gadai wajib melunasi utangnya dengan memperhatikan kurs harga emas yang berlaku pada saat pelunasan utang dilakukan. Cara pembayaran yang digunakan penerima gadai sama dengan teori nilai waktu uang, di mana uang saat ini lebih bernilai dibandingkan uang pada masa yang akan datang. Dengan demikian, pemberi gadai melunasi utang yang jumlahnya lebih banyak dibandingkan ketika ia meminjam. Hasil penelitian menunjukkan bahwa: pertama, Gadai tanah dengan kurs harga emas di Desa Plakpak Kecamatan Pegantenan telah lama berlangsung dan masih belum berakhir hingga sekarang. Transaksi tersebut hanya terjadi di antara kedua belah pihak yang masih memiliki hubungan kerabat dengan menyepakati pelunasan utang yang disetarakan pada kurs harga emas. Adapun tanah jaminan berada di bawah pengelolaan pihak Penerima gadai sampai utang dilunasi. Kedua, gadai tanah dengan kurs harga emas di desa Plakpak menurut tinjauan Hukum Islam adalah mubah sepanjang adanya kerelaan di antara kedua belah pihak dan untuk menjaga kestabilan nilai mata uang. Di samping itu, pemanfaatan barang gadai tidak sesuai dengan ketentuan syariah, dikarenakan tanah jaminan dikuasai dan dikelola secara penuh oleh penerima gadai. (Land pawn with the gold price in Plakpak village occurs with a payment system in which the pledge is obliged to repay the debt by observing the gold price exchange rate in effect at the time the debt is repaid. The payment method used by the pawn recipient is the same as the theory of time value of money, where money of today is more valuable than money in the
\end{abstract}


Sihabuddin

Wasilatur Rohmaniyah

future. Thus, the mortgage provider repays the debt which is more than the amount he borrowed. The results of the study show that: first, the land pawn with the gold price exchange rate in the Plakpak Village of Pegantenan Subdistrict has long been underway and still has not ended until now. The transaction only occurred between the two parties who still have a family relationship by agreeing to repay the debt which is equal to the gold price exchange rate. The collateral land is under the management of the pawn party until the debt is repaid. Second, land pawn with the price of gold in the village of Plakpak according to Islamic law review is muted as long as there is willingness between the two parties and to maintain the stability of the currency. In addition, the use of pledged goods is not in accordance with sharia provisions, because the collateral land is fully controlled and managed by the pledge recipient.)

Kata Kunci:

Gadai Tanah, Kurs Harga Emas, Hukum Islam, Desa Plakpak

\section{Pendahuluan}

Dalam Islam hubungan antar sesama manusia disebut muamalah; hukum syar'i yang mengatur hubungan hukum manusia di bidang harta benda, seperti jual beli, sewa menyewa, wakaf, hibah, rahn, hiwalah (pengalihan hutang) dan sebagainya. ${ }^{1}$ Sebagai makhluk sosial, ber-muamalah merupakan sebuah keniscayaan. Realita kehidupan menunjukkan bahwa keseharian manusia sebagian besar dihabiskan untuk berinteraksi dengan sesamanya. Dengan demikian ber-muamalah dapat dikategorikan sebagai salah satu kebutuhan manusia yang tak terelakkan lagi.

Hubungan antar sesama manusia amat beragam dan dinamis seiring berkembangnya zaman. Misalnya saja, transaksi pinjammeminjam, utang-piutang, jual-beli, gadai, dan berbagai transaksi lainnya, yang erat kaitannya dengan pemenuhan kebutuhan manusia. Dengan kata lain, berbagai akad tersebut dapat menjadi perantara atau penghubung seorang individu guna memenuhi keperluan jasmani maupun rohani. Mengingat kebutuhan setiap manusia

${ }^{1}$ Fathurrahman Djamil, Hukum Ekonomi Islam-Sejarah, Teori dan Konsep, (Jakarta: Sinar Grafika, 2015), hlm. 25. 
berbeda-beda sesuai dengan kebutuhan tubuhnya, gaya hidup, selera, sosial budaya, ekonomi maupun topologi wilayahnya.

Secara garis besar, bila ditinjau dari sisi topologi wilayah, Indonesia merupakan kawasan agraris atau pertanian yang mayoritas penduduknya bermata pencaharian sebagai petani. Kondisi semacam ini mendorong masyarakat untuk menyimpan harta bendanya dalam bentuk barang tidak bergerak. Dalam artian tanah menjadi aset yang paling berharga bagi penduduk setempat. Tetapi, di sisi lain, keadaan tersebut dapat menimbulkan kesulitan likuiditas ketika masyarakat membutuhkan dana secara tunai dalam waktu cepat. Sehingga untuk mengatasi permasalahan ini, mereka yang membutuhkan lebih cenderung meminjam sejumlah dana pada anggota masyarakat lain yang berkemampuan finansial lebih baik dengan cara menjaminkan barang berharganya berupa tanah sebagai agunan utang. Konsep sejenis ini dikenal dengan istilah gadai. ${ }^{2}$

Fakta menunjukkan eksistensi gadai cukup berkembang di masyarakat, khususnya bagi mereka kaum ekonomi kelas menengah ke bawah. Bahkan praktik gadai telah diaplikasikan sejak zaman Rasulullah saw. Tentunya gadai menjadi alternatif terbaik untuk menyelesaikan permasalahan mendesak yang sedang dihadapi. Dalam pelaksanaannya, akad gadai akan sempurna bila mana barang jaminan telah berada di bawah penguasaan pemegang gadai/pemberi pinjaman. Barang ini akan terus dikuasai oleh penerima gadai sampai pemberi gadai melunasi kewajibannya. ${ }^{3}$ Tetapi murtahin tidak diperkenankan memanfaatkan barang jaminan. Dalam beberapa literatur dijelaskan bahwa penerima gadai diperbolehkan mengambil manfaat sepanjang untuk menutupi biaya perawatan yang dikeluarkannya.

Konsep di atas tidak selamanya sejalan dengan penerapan di lapangan. Kebanyakan masyarakat tetap memanfaatkan barang jaminan dengan dalih barang gadai di bawah penguasaannya, sebagaimana contoh kasus yang menjadi kajian di Desa Plakpak Kecamatan Pegantenan Kabupaten Pamekasan ini, sebuah desa yang mayoritas penduduknya berprofesi sebagai petani. Dalam praktiknya,

\footnotetext{
${ }^{2}$ M. Nur Rianto Al Arif, Lembaga Keuangan Syariah Suatu Kajian Teoritis Praktis, (Bandung: Pustaka Setia, 2012), hlm. 275.

${ }^{3}$ Rachmat Syafe'i, Fiqih Muamalah, (Bandung: Pustaka Setia, 2001), hlm. 173.
} 
Sihabuddin

Wasilatur Rohmaniyah

pemberi gadai menggadaikan tanah sawah miliknya kepada penerima gadai untuk dijadikan jaminan. Kemudian penerima gadai memanfaatkan tanah tersebut seperti barang miliknya sendiri demi memenuhi kebutuhannya. Adapun sistem pembayaran dari transaksi ini, pemberi gadai wajib melunasi utangnya dengan memperhatikan kurs harga emas yang berlaku pada saat pelunasan utang dilakukan. Apabila ditelaah lebih lanjut, cara pembayaran yang digunakan penerima gadai sama dengan teori nilai waktu uang, di mana uang saat ini lebih bernilai dibandingkan uang pada masa yang akan datang. ${ }^{4}$ Dengan demikian Pemberi gadai wajib membayar kompensasi yang disesuaikan dengan kurs harga emas pada saat pelunasan utang.

Hal inilah yang kemudian menjadi masalah ketika penebusan barang gadai disesuaikan dengan kurs harga emas. Terdapat dua kemungkinan berupa kenaikan dan penurunan kurs harga emas. Kondisi semacam ini mengakibatkan pihak Pemberi gadai tidak mampu melunasi utangnya hingga sekarang, mengingat harga emas dari tahun ke tahun terus mengalami kenaikan.

Berdasarkan uraian konteks penelitian di atas, maka fokus penelitian ini adalah bagaimana pelaksanaan gadai tanah dengan kurs harga emas di Desa Plakpak Kecamatan Pegantenan dan bagaimana tinjauan hukum Islam terhadap gadai tanah dengan kurs harga emas di Desa Plakpak Kecamatan Pegantenan tersebut.

\section{Qard dan Rahn Menurut Fiqh}

\section{Qardh/Utang}

\section{a. Definisi Utang/Qardh}

Secara etimologi, qardh berasal dari kata qaradha yang berarti (potongan). Diartikan demikian karena orang yang memberikan utang (Muqrid) memotong sebagian dari hartanya untuk diberikan kepada orang yang menerima utang (Muqtarid). ${ }^{5}$

Utang/qardh merupakan pemberian harta kepada orang lain yang dapat ditagih atau diminta kembali.

\footnotetext{
${ }^{4}$ Veithzal Riva'i dan Andi Buchari, Islamic Economics Ekonomi Syariah Bukan Opsi Tetapi Solusi!, (Jakarta: Bumi Aksara, 2013), hlm. 466.

${ }^{5}$ Asmaji Muchtar, Dialog Lintas Madzhab Fiqh Ibadah dan Muamalah, Ed. 1, Cet. Ke-1, (Jakarta: Amzah, 2015), hlm. 519.
} 
Tinjauan Hukum Islam Terhadap Gadai Tanah dengan Kurs Harga Emas (Studi Kasus di Desa Plakpak Kecamatan Pagentenan)

\section{b. Dasar Hukum Utang/Qardh}

Secara umum utang diperbolehkan dalam Islam berdasarkan beberapa landasan syariahnya, antara lain:

\section{1) Al-Qur'an}

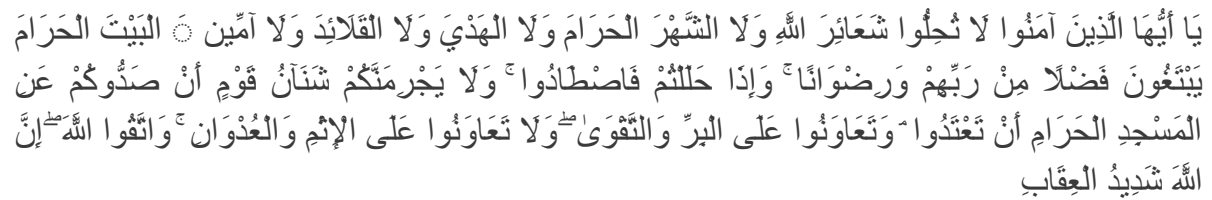

Artinya: "Hai orang-orang yang beriman, janganlah kamu melanggar syi'ar-syi'ar Allah, dan jangan melanggar kehormatan bulan-bulan haram, jangan (mengganggu) binatang-binatang had-ya, dan binatang-binatang qalaa-id, dan jangan (pula) mengganggu orang-orang yang mengunjungi Baitullah sedang mereka mencari kurnia dan keredhaan dari Tuhannya dan apabila kamu telah menyelesaikan ibadah haji, Maka bolehlah berburu. dan janganlah sekali-kali kebencian(mu) kepada sesuatu kaum karena mereka menghalang-halangi kamu dari Masjidilharam, mendorongmu berbuat aniaya (kepada mereka). dan tolong-menolonglah kamu dalam (mengerjakan) kebajikan dan takwa, dan jangan tolongmenolong dalam berbuat dosa dan pelanggaran. dan bertakwalah kamu kepada Allah, Sesungguhnya Allah Amat berat siksa-Nya." (QS. Al-Maidah:2) ${ }^{6}$

\section{2) Al-Hadis}

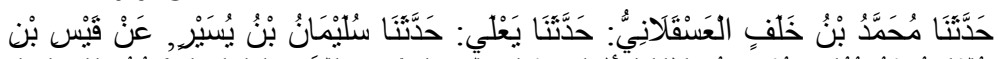

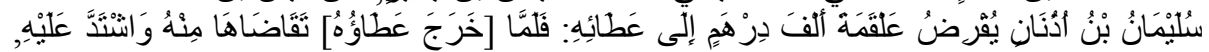

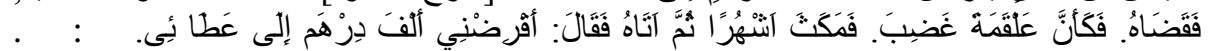

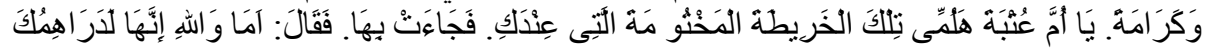

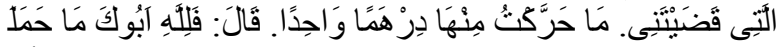

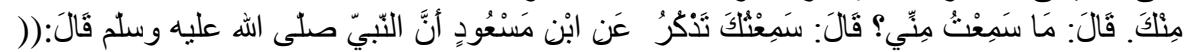

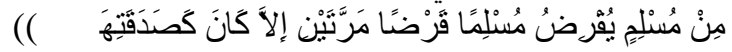

\footnotetext{
${ }^{6}$ Kementerian Agama RI, Mushaf 'Aisyah, Al-Qur'an dan Terjemah untuk
} Wanita,hlm. 106 
Sihabuddin

Wasilatur Rohmaniyah

Artinya: Muhammad bin Khalaf al-Asqalani menyampaikan kepada kami dari Ya'la, dari Sulaiman bin Yusair bahwa Qais bin Rumi berkata, "Sulaiman bin Udzunan pernah memberikan pinjaman kepada Alqamah sebesar 1000 dirham dengan tempo sampai tiba waktu gajinya. Tatkala dia sudah menerima gajinya, Sulaiman pun menagihnya dan menekannya sehingga Alqamah terpaksa membayarnya, seolah terlihat marah. Beberapa bulan kemudian dia (Alqamah) pun datang lagi kepadanya dan berkata, 'Berilah pinjaman kepadaku 1000 dirham hingga tiba waktu gajianku.' Sulaiman menjawab, 'Baik, dan dengan senang hati. Wahai Ummu Utbah, berikan kepadaku pundi-pundi yang disegel yang ada padamu.' Wanita itu pun membawanya. Dia (Sulaiman bin Udzunan) berkata, 'Demi Allah, ini adalah dirhammu yang telah engkau bayarkan kepadaku. Aku tidak menyentuh satu dirham pun darinya walau sedikit.' Alqamah berkata, 'Demi Allah, apa yang membuatmu melakukan itu terhadapku?' Dia menjawab, 'Apa yang pernah aku dengar darimu.' Dia bertanya, 'Apa yang pernah engkau dngar dariku?' Dia berkata, 'Aku mendengar engkau menyebutkan dari Ibnu Mas'ud bahwa nabi Saw. bersabda 'tidak seorang muslim pun memberi pinjaman kepada orang muslim lainnya dua kali melainkan seperti sedekah satu kali.' Alqamah berkata, "Ya, demikian yang diceritakan Ibnu Mas'ud kepadaku." (HR. Ibnu Majah $)^{7}$

\section{c. Barang yang Sah Dijadikan Utang/Qardh}

Beberapa madzhab mengemukakan pendapatnya tentang barang yang sah dijadikan utang. Ulama Hanafiyah berpendapat bahwa utang akan sah pada harta mitsil; yakni sesuatu yang tidak terjadi perbedaan yang menyebabkan terjadinya perbedaan nilai atau harta yang memiliki padanan di pasar, seperti barang-barang yang dapat ditimbang, ditakar maupun dihitung. ${ }^{8}$

Ulama Malikiyah, Syafi'iyah, dan Hanabilah membolehkan qardh pada setiap benda yang tidak dapat diserahkan, baik yang

\footnotetext{
${ }^{7}$ Abu Abdullah Muhammad bin Yazid al-Qazwini Ibnu Majah, Ensiklopedia Hadits 8; Sunan Ibnu Majah, Cet. 1, Saifuddin Zuhri, (Jakarta: Almahira, 2013), hlm. 433. ${ }^{8}$ Al-Huskhafi, (Ibid, hlm. 154)
} 
ditakar maupun ditimbang, seperti emas, perak, barang dagangan, hewan maupun benda lainnya yang dapat dihitung.

\section{d. Qardh Manfaat}

Adapun pendapat para ulama tentang qardh manfaat, antara lain: pendapat yang paling unggul dari ulama Hanafiyah menyatakan bahwa setiap qardh pada benda yang mendatangkan manfaat diharamkan jika menggunakan syarat. Misalnya seperti syarat memberikan makan muqrid selama muqtarid belum melunasi utang. Apabila tidak disyaratkan kemanfaatannya, maka qardh semacam ini diperbolehkan.

\section{e. Penangguhan dan Cara Pembayaran Utang/Qardh}

Adapun ulama Hanafiyah menetapkan keharusan untuk menangguhkan qardh pada 4 keadaan: ${ }^{9}$

1) Wasiat, seperti mewasiatkan untuk penangguhan sejumlah harta dan ditangguhkan pembayarannya selama setahun, maka ahli waris tidak boleh mengambil penggantinya dari Muqtarid sebelum habis waktu setahun.

2) Diasingkan, qardh diasingkan kemudian pemiliknya menangguhkannya sebab penangguhan pada waktu itu diharuskan.

3) Berdasarkan keputusan hakim.

4) Hiwalah, yakni pemindahan utang.

\section{Gadai/Rahn}

\section{a. Definisi Gadai/Rahn}

Secara bahasa, gadai atau rahn berarti yakni tetap dan lama. Selain itu, rahn juga dinamai yang bermakna penahanan. ${ }^{10}$ Definisi di atas selaras dengan pengertian gadai yang terdapat dalam buku Islamic Banking bahwa gadai adalah menahan atau menangguhkan salah satu harta milik si rahin sebagai jaminan atas pinjaman yang diterimanya. ${ }^{11}$

\footnotetext{
${ }^{9}$ Rachmat Syafe'’i, Fiqih Muamalah, hlm. 154

${ }^{10}$ M. Nur Rianto Al-Arif, Lembaga Keuangan Syariah-Suatu Kajian Teoretis Praktis, hlm. 279.

${ }^{11}$ Muhammad Syafi'i Antonio, Islamic Banking-Bank Syariah: Dari Teori Ke

Praktik, Cet. Kedua puluh enam, (Jakarta: Gema Insani Press, 2016), hlm. 128.
} 
Sihabuddin

Wasilatur Rohmaniyah

Gadai/rahn merupakan suatu perjanjian dengan menjadikan barang milik pengutang sebagai jaminan utang yang sewaktu-waktu barang tersebut dapat dijadikan ganti pelunasan utang.

\section{b. Sifat Gadai/Rahn}

Secara umum rahn merupakan suatu transaksi yang bersifat derma. Hal ini dikarenakan barang yang diberikan pengutang/penggadai (rahin) kepada pemberi utang/penerima gadai (murtahin) tidak ditukar dengan sesuatu. ${ }^{12}$ Adapun yang diberikan murtahin kepada rahin ialah utang, bukan penukar atas barang yang digadaikan.

\section{c. Rukun Gadai/Rahn}

Secara umum menurut jumhur ulama, rukun rahn meliputi: ${ }^{13}$

1) Rahin (orang yang memberikan jaminan/yang menggadaikan);

2) Murtahin (orang yang menerima jaminan/yang menerima gadai);

3) Marhun (barang yang digadaikan);

4) Marhun Bih (utang); dan

5) Sighat (ijab-qabul); ijab merupakan pernyataan penawaran, sementara qabul adalah penerimaan atau pernyataan persetujuan. ${ }^{14}$

\section{d. Syarat-syarat Gadai/Rahn}

Adapun syarat-syarat gadai mencakup persyaratan bagi aqid (rahin dan murtahin), syarat sighat, marhun bih, dan syarat pada marhun; sebagai berikut:

1) Persyaratan Aqid

Persyaratan ini mencakup syarat bagi rahin/orang yang menggadaikan dan murtahin/orang yang menerima gadai, antara lain: ${ }^{15}$

a) Cakap bertindak hukum

b) Layak melakukan transaksi pemilikan

2) Syarat Sighat

\footnotetext{
${ }^{12}$ Ibid.

${ }^{13}$ M. Nur Rianto Al-Arif, Lembaga Keuangan Syariah-Suatu Kajian Teoretis Praktis, hlm. 284

${ }^{14}$ Juhaya S. Pradja, Ekonomi Syariah, Cet. pertama, (Bandung: Pustaka Setia, 2012), hlm. 112.

${ }^{15}$ Rachmat Syafe'i, Fiqih Muamalah, hlm. 162-164.
} 
Sighat tidak diperbolehkan terikat pada syarat tertentu maupun waktu-waktu di masa depan. Misalnya pada barang gadai berupa hewan, mensyaratkan agar diberi makan makanan tertentu. Syarat semacam ini menyebabkan akad menjadi batal karena rahn mempunyai sisi pelepasan barang dan pemberian utang seperti halnya akad jual beli.

3) Syarat Marhun Bih

Adapun dalam transaksi gadai, syarat-syarat marhun bih menurut para ulama, yaitu: ${ }^{16}$

a) Hak yang wajib diberikan/diserahkan kepada pemiliknya;

b) Memungkinkan pemanfaatannya, jika sesuatu yang menjadi utang tidak dapat dimanfaatkan, maka tidak sah hukumnya;

c) Dapat dikuantifikasikan atau dihitung jumlahnya. Apabila tidak dapat diukur, maka hukumnya tidak sah; dan

d) Utang boleh dilunasi dengan jaminan yang telah diserahkan.

\section{e. Berakhirnya Akad Gadai}

Akad rahn dapat berakhir atau habis dengan beberapa keadaan sebagai berikut:17

1) Barang telah diserahkan pada pemiliknya/pemberi gadai;

2) Rahin melunasi utangnya;

3) Pembebasan utang;

4) Dijual dengan perintah hakim atas permintaan rahin; meskipun telah jatuh tempo dan rahin tidak melunasi utangnya serta tidak mengizinkan barangnya untuk dijual, maka hakim berhak memaksanya guna menjual barang jaminan tersebut.

5) Pembatalan oleh murtahin; rahn dipandang habis jika murtahin membatalkan rahn meskipun tanpa seizin rahin.

\footnotetext{
${ }^{16}$ Nasrun Haroen, Fiqh Muamalah, Cet. Kedua, (Jakarta:Gaya Media Pratama, 2007), hlm. 255.

${ }^{17}$ Muhammad Syafi'i Antonio (M. Nur Rianto Al-Arif, Lembaga Keuangan SyariahSuatu Kajian Teoretis Praktis, hlm. 290).
} 
Sihabuddin

Wasilatur Rohmaniyah

Namun jika sebaliknya, tidak batal jika rahin yang membatalkan.

6) Rusaknya barang rahn bukan karena tindakan atau penggunaan oleh murtahin; sebagian fuqaha seperti Imam Abu Hanifah dan jumhur fuqaha Kufah berpendapat bahwa murtahin bertanggung jawab jika barang gadai rusak di tangannya. Tetapi, menurut Imam Syafi'i, Ahmad, Abu Tsaur dan mayoritas ahli hadits berpendapat bahwa barang gadai adalah amanat. Sehingga penerima gadai tidak dapat mengambil tanggung jawab atas kehilangan barang jaminan.

7) Memanfaatkan barang jaminan dengan penyewaan, hibah atau sedekah, baik dari pihak rahin ataupun murtahin.

\section{Metode Penelitian}

Penelitian ini adalah penelitian deskriptif dengan pendekatan kualitatif. Metode pengumpulan data diperoleh melalui wawancara, observasi dan dokumentasi. Lokasi yang menjadi objek penelitian adalah Desa Plakpak Kecamatan Pegantenan Kabupaten Pamekasan. Alasan peneliti memilih desa ini karena banyaknya jumlah transaksi akad gadai dengan kurs harga emas yang dilakukan masyarakat setempat. Umumnya hal tersebut lazim dipraktikkan semenjak 2 dekade terakhir.

\section{Paparan Data Dan Temuan Penelitian}

a. Pelaksanaan Gadai Tanah dengan Kurs Harga Emas di Desa Plakpak Kecamatan Pegantenan

Gadai tanah di desa Plakpak memang sudah lazim dipraktikkan oleh sebagian besar masyarakat setempat. Namun seiring berjalannya waktu, perlahan-lahan masyarakat mulai meninggalkan transaksi serupa yang masih tradisional. Mereka lebih memilih mencari pinjaman dana pada lembaga-lembaga kekinian, seperti koperasi, BMT, ataupun bank.

Tetapi, beberapa kasus gadai di desa Plakpak masih terus berlanjut hingga saat ini. Hal ini karena pihak peminjam uang/pemberi gadai belum mampu melunasi utang. Adapun faktor penyebabnya yakni besaran utang yang disetarakan dengan kurs 
harga emas, sehingga jumlah utang akan terus bertambah dari waktu ke waktu mengikuti kenaikan nilai emas.

Gadai tanah dengan kurs harga emas di desa Plakpak yang telah lama diterapkan, tidak menuai reaksi negatif di kalangan masyarakat sekitar. Mereka tidak mempermasalahkan transaksi ini selagi kedua belah pihak melakukannya secara sukarela dan pihak Pemberi gadai benar-benar membutuhkan pinjaman dana. Walaupun di satu sisi, perjanjian gadai dilakukan tanpa melibatkan pihak ketiga, seperti Kepala desa maupun staf-stafnya.

b. Tinjauan hukum Islam terhadap gadai tanah dengan kurs harga emas di Desa Plakpak Kecamatan Pegantenan

Selanjutnya setelah mendapatkan data hasil wawancara dan observasi tentang penerapan gadai tanah dengan kurs harga emas di desa Plakpak, peneliti ingin mengetahui bagaimana pandangan hukum Islam terhadap fenomena ini. Oleh karenanya, peneliti mewawancarai beberapa tokoh agama di desa Plakpak yang diyakini mempunyai wawasan luas baik agama maupun umum serta memiliki sudut pandang yang netral dan bijak dalam menyikapi setiap permasalahan. Hal ini peneliti lakukan untuk mendapatkan keterangan terkait pendapatnya tentang tinjauan hukum Islam terhadap gadai tanah dengan kurs harga emas di desa Plakpak yang nantinya dapat peneliti jadikan salah satu bahan acuan dalam menentukan status hukum peristiwa tersebut.

Dalam hal ini, diperlukan metode penetapan hukum Hilah untuk mengetahui apakah gadai tanah dengan kurs harga emas benar-benar halal diterapkan atau sebaliknya. Menurut tokoh agama yang terakhir didasarkan pada teori hilah, akad gadai ini boleh dilakukan dengan syarat tujuannya bukan untuk mengambil keuntungan/tambahan dari transaksi utang. Adapun mengenai pemanfaatan tanah gadai boleh dikelola oleh Murtahin atas izin Rahin.

Dengan demikian, ketiga tokoh agama yang peneliti mintai keterangan terkait status hukum gadai tanah dengan kurs harga emas memberikan kesimpulan bahwa praktuk tersebut adalah mubah. Sedangkan pemanfaatan tanah gadai yang dilakukan oleh pihak Murtahin juga mubah, dengan syarat seizin Rahin dan sekedar untuk mengganti biaya pemeliharaan saja. 
Sihabuddin

Wasilatur Rohmaniyah

\section{Temuan Penelitian:}

Adapun temuan-temuan penelitian dari topik-topik penelitian yang peneliti dapatkan selama melakukan observasi dan wawancara ialah sebagai berikut:

1. Pelaksanaan Gadai tanah dengan kurs harga emas di Desa Plakpak Kecamatan Pegantenan

a. Kesepakatan gadai tanah dengan kurs harga emas awalnya diutarakan oleh pihak Pemberi gadai. Dengan kata lain pelunasan utang dengan diukur pada kurs harga emas merupakan inisiatif pihak Pemberi gadai. Hal ini dilakukan dengan beberapa tujuan; pertama, agar pihak Penerima gadai lekas mengiyakan pinjaman dana; kedua, untuk memberikan jaminan keamanan terhadap kestabilan uang di kemudian hari, sehingga tidak merugikan Penerima gadai; ketiga, sebagai bentuk motivasi bagi Pemberi gadai agar segera melunasi utang.

b. Dalam akad gadai tanah dengan kurs harga emas, masyarakat desa Plakpak hanya melibatkan para pihak yang berkepentingan saja tanpa sepengetahuan perangkat desa.

c. Alasan pihak Pemberi gadai melakukan gadai ialah untuk memenuhi kebutuhan hidup yang mendesak.

d. Pemanfaatan tanah jaminan dilakukan oleh Penerima gadai tanpa mempertimbangkan biaya pemeliharaan yang dikeluarkan.

e. Masyarakat merespon positif terhadap gadai tanah dengan kurs harga emas di desa Plakpak.

2. Tinjauan hukum Islam terhadap gadai tanah dengan kurs harga emas di Desa Plakpak Kecamatan Pegantenan

a. Gadai tanah dengan kurs harga emas memiliki status mubah atau boleh dilakukan selama kedua belah pihak saling rela akan transaksi tersebut dan tujuan disetarakannya utang dengan kurs harga emas benar-benar baik, bukan untuk mengambil keuntungan/tambahan di dalamnya.

b. Pemanfaatan tanah gadai boleh dilakukan oleh pihak Murtahin sepanjang mendapat izin dari pihak Rahin dan sekedar untuk mengganti biaya pemeliharaan. 


\section{Kesimpulan}

Pada bagian ini, peneliti akan menyimpulkan hasil pembahasan mengenai gadai tanah dengan kurs harga emas di Desa Plakpak Kecamatan Pamekasan, sebagai berikut:

1. Gadai tanah dengan kurs harga emas di Desa Plakpak Kecamatan Pegantenan telah lama terjadi dan masih belum berakhir hingga saat ini. Transaksinya hanya terjadi di antara kedua belah pihak yang masih memiliki hubungan kerabat dengan menyepakati pelunasan utang disetarakan pada kurs harga emas. Adapun tanah jaminan berada di bawah pengelolaan pihak Penerima gadai sampai utang dilunasi.

2. Tinjauan hukum Islam terhadap gadai tanah dengan kurs harga emas di Desa Plakpak Kecamatan Pegantenan

a. Pelaksanaan gadai tanah dengan kurs harga emas di Desa Plakpak Kecamatan Pegantenan dari sisi rukun telah sesuai dengan ketentuan syariah.

b. Adapun dari sisi syarat, pelunasan utang dengan disetarakan pada kurs harga emas sah-sah saja untuk dilakukan. Hal ini karena baik pihak Pemberi gadai maupun Penerima gadai menyepakatinya secara sukarela. Mereka sepakat dengan tujuan demi mencegah kerugian bagi pihak Penerima gadai di kemudian hari, mengingat nilai mata uang bisa mengalami fluktuasi/ketidakstabilan. Selain itu, juga sebagai motivasi bagi Pemberi gadai agar tidak lengah terhadap kewajibannya membayar utang.

c. Dari segi pemanfaatan barang gadai, gadai dengan kurs harga emas di Desa Plakpak Kecamatan Pegantenan tidak sesuai dengan ketentuan syariah, dikarenakan tanah jaminan dikuasai dan dikelola secara penuh oleh Penerima gadai. 
Sihabuddin

Wasilatur Rohmaniyah

\section{Daftar Pustaka}

Ahkamul Fuqaha Solusi Problematika Aktual Hukum Islam, Keputusan Muktamar, Munas dan Konbes Nahdlatul Ulama (1926-2010). Surabaya: Khalista. 2011.

Al Arif, M. Nur Rianto.Lembaga Keuangan Syariah Suatu Kajian Teoritis Praktis.Bandung: Pustaka Setia. 2012.

Al Hurani,Syaikhul Islam Taqiyyudin Ahmad bin Taimiyah.Kumpulan Fatwa Ibnu Taimiyah.Amir Hamzah.Jakarta: Pustaka Azzam. 2014.

Al-Bukhari,Abu Abdullah Muhammad bin Ismail.Ensiklopedia Hadits; Shahih al-Bukhari 1.Cet. 1.Masyhar dan Muhammad Suhadi.Jakarta: Almahira. 2011.

Al-Fannani,Zainuddin bin Abdul Aziz Al-Malibari.Terjemahan Fathul $M u^{\prime}$ in Jilid I. K.H. Moch Anwar dkk.Bandung: Sinar Baru Algensindo. 2004.

Al-Jama'ili, Abi Muhammad Abdillah bin Ahmad bin Muhammad bin Qadamah al-Muqaddasi. Al-Mughni. juz 6. Riyadh: Darul 'Alim al-Kutub.

Al-Mahalli, Imam Jalaluddin dan Imam Jalaluddin As-Suyuti. Terjemahan Tafsir Jalalain Berikut Asbabun Nuzul. Jilid 1. Cet. Ke7. Bahrun Abubakar. Bandung: Sinar Baru Algensindo. 2009.

Antonio,Muhammad Syafi'i.Islamic Banking-Bank Syariah: Dari Teori Ke Praktik.Cet. Kedua puluh enam.Jakarta: Gema Insani. 2016.

Arikunto, Suharsimi.Prosedur Penelitian. Jakarta: Renika Cipta. 2006.

As-Sijistani, Abu Dawud Sulaiman bin al-Asy'ats al-Azdi. Ensiklopedia Hadits 5; Sunan Abu Dawud. Muhammad Ghazali dkk. Jakarta: Almahira. 2013.

At-Tirmidzi, Abu Isa Muhammad bin Isa. Ensiklopedia Hadits 6; Jami' at-Tirmidzi. Tim Darussunnah. Jakarta: Almahira. 2013.

Az-Zuhaili,Wahbah. Fiqih Islam Wa Adillatuhu 6. Abdul Hayyie alKattani dkk. Cet. Ke-1. Jakarta: Gema Insani. 2011.

Djamil, Fathurrahman. Hukum Ekonomi Islam-Sejarah, Teori, dan Konsep. Jakarta: Sinar Grafika. 2015.

Fatwa Dewan Syariah Nasional Nomor: 25/DSN-MUI/III/2002 Tentang Rahn, DSN MUI Pdf.

Ghony, M. Djunaidi dan Fauzan Almanshur. Metode Penelitian Kualitatif-Edisi Revisi. Jogjakarta: Ar-Ruzz Media. 2014. 
Haroen, Nasrun.Figh Muamalah. Cet. Kedua.Jakarta: Gaya Media Pratama. 2007.

Himpunan Fatwa Keuangan Syariah Dewan Syariah Nasional MUI. Jakarta: Penerbit Erlangga. 2014.

Ismail. Perbankan Syariah.Ed. Pertama. Cet. Ke-3. Jakarta: Kencana Prenada Media Group 2014.

Isti'anah. Praktek Gadai Tanah Ditinjau dari Hukum Islam (Studi di Desa Harjawinangun Kec. Balapulang Kab. Tegal). Skripsi Penelitian. UIN Sunan Kalijaga. Yogyakarta. 2009.

Kementerian Agama RI. Mushaf 'Aisyah.Al-Qur'an dan Terjemah untuk Wanita. Bandung: Jabal. 2010.

Kompilasi Hukum Ekonomi Syariah. Edisi Revisi.Cet. Ke-1. Jakarta: Kencana Prenada Media Group.2009.

Majah, Abu Abdullah Muhammad bin Yazid al-Qazwini Ibnu. Ensiklopedia Hadits 8; Sunan Ibnu Majah. Cet. 1. Saifuddin Zuhri.Jakarta: Almahira. 2013.

Moleong, Lexy J. Metode Penelitian Kualitatif.Bandung: Remaja Rosda Karya. 2000.

Muchtar, Asmaji. Dialog Lintas Madzhab Figh Ibadah dan Muamalah. Ed. 1. Cet. Ke-1. Jakarta: Amzah. 2015.

Pradja, Juhaya S. Ekonomi Syariah. Cet. Pertama.Bandung: Pustaka Setia. 2012.

Quthb, Syahid Sayyid. Tafsir fi Zhilalil-Qur'an. Cet. Ke-1. As'ad Yasin dkk. Jakarta: Gema Insani Press. 2000.

Riva'i,Veithzal dan Andi Buchari. Islamic Economics Ekonomi Syariah Bukan Opsi Tetapi Solusi!. Jakarta: Bumi Aksara. 2013.

Sholihin, Ahmad Ifham.Buku Pintar Ekonomi Syariah. Cet. Pertama. Jakarta: Gramedia Pustaka Utama. 2010.

Sugiyono. Metode Penelitian Bisnis.Bandung: Alfabeta. 2009.

Suhriyanto,Ach. Praktik Gadai Tanah Sawah di Desa Sanatengah Kecamatan Pasean Kabupaten Pamekasan Ditinjau dari Hukum Ekonomi Islam. Skripsi Penelitian. STAIN Pamekasan. Pamekasan. 2014.

Suwartono. Dasar-dasar Metodologi Penelitian. Yogyakarta: Andi Offset. 2014.

Syafe'i,Rachmat. Fiqih Muamalah. Bandung: Pustaka Setia. 2001. 
Sihabuddin

Wasilatur Rohmaniyah

Uha, Ismail Nawawi. Isu-Isu Ekonomi Islam-Kompilasi Pemikiran dan Teori Menuju Praktik di Tengah Arus Ekonomi Global-Buku 4 Nalar Bisnis. Jakarta: VIV Press. 2013. 